\title{
A PERSONAGEM PROUSTIANA E O CUBISMO*
}

\author{
Sabrina Ribeiro Baltor ${ }^{* * *}$
}

Resumo: Marcel Proust era grande conbecedor e amante das artes plásticas. Apresento um estudo sobre a construção dos personagens proustianos em $\mathrm{O}$ Caminho de Guermantes por meio das técnicas pictóricas desenvolvidas pelos pintores cubistas. Destaco o método de reprodução de um objeto a partir de vários ângulos de visão, transportado por Proust na descrição de um rosto de um personagem, constituído pelo conjunto de várias imagens desta face textual.

Este ensaio representa um dos resultados obtidos ao longo de um ano de pesquisa ${ }^{1}$ acerca das relações estabelecidas entre a literatura proustiana e a pintura cubista, tanto no que concerne à técnica de construção textual, inspirada nas técnicas pictóricas desenvolvidas por esta escola moderna, quanto ao efeito estético que ela produz, de modo a acrescentar um novo jogo de sentidos no qual o aspecto formal do texto desempenha, em determinadas passagens da obra de Marcel Proust, o mesmo papel de gerador de significados que o conteúdo.

*Recebido para publicação em abril de 2000.

${ }^{* *}$ Mestranda em Língua e Literatura Francesa na Universidade Federal do Rio de Janeiro.

${ }^{1}$ Pesquisa realizada com bolsa PIBIC/CNPq. 
No desenvolvimento deste estudo, pretendo exibir um panorama do movimento plástico cubista, destacando as técnicas pictóricas transportadas por Proust para seu texto; mencionar as semelhanças já apontadas por alguns críticos literários entre a estética proustiana e a estética cubista e, por fim, analisar textos de $O$ Caminbo de Guermantes em que personagens são descritos seguindo a forma de representação da escola plástica cujo maior representante era Picasso.

A pintura cubista seguiu o caminho aberto pela escola impressionista, na medida em que também formulou novas técnicas picturais que transformaram o universo da representação nas artes plásticas no início do século $\mathrm{XX}$, distanciando-se ainda mais do modelo acadêmico naturalista, pautado na geometria euclidiana, que visava alcançar a representação mais idêntica à "realidade" e, como estética, dominou a comunidade artística desde o século $\mathrm{XV}$ até o final do século XIX. A partir das inovações promovidas por Boudin, Courbet e Monet que modificaram desde o tema dos quadros até a técnica das sombras, passando pela adoção da luz como a grande responsável pela alteração dos objetos retratados e, culminando com a representação do motivo através do olhar atento e, algumas vezes, subjetivo do artista, o Impressionismo rompe com as normas acadêmicas e amarga críticas férreas à época das suas primeiras exposições. No entanto, após suportar o ataque maciço da opinião pública e dos mais respeitáveis críticos de arte, a qualidade de sua pintura é reconhecida e seus quadros estudados de maneira a facultar à geração de novos pintores uma ousadia ainda maior na escolha dos temas e, sobretudo, na criação de novas técnicas de representação no campo das artes plásticas.

Desta maneira, pintores como Braque e Picasso, fascinados pela pintura de Cézanne, pelos movimentos modernos que emergiam na Europa no início do século XX e pela chamada arte negra, empreenderam uma busca incessante por novos métodos de 
representação, menos associados à realidade visual cultivada pela pintura acadêmica e mais próximos, num primeiro momento, de uma realidade que se queria transportada inteira para a tela, respeitando toda a sua complexidade, tentando adequar de todos os modos imagináveis os objetos de três dimensões em um receptáculo de duas dimensões: a tela.

O crítico de arte Joseph-Emile Muller, em seu livro L'Art Moderne, defende pintores que, a exemplo de Braque e Picasso, buscam novos meios de representar o espaço na superfície do quadro. Muller afirma que a visão artística divulgada pela pintura acadêmica naturalista não é de modo algum o estado normal da arte:

Cependant, si le naturalisme n'est pas l'état normal de l'art, n'en est-il pas du moins l'état idéal? N'est-il pas l'unique moyen de donner de la réalité une image vraie? Il est seulement le moyen de représenter les cboses telles qu'elles apparaissent à nos yeux lorsque nous les considérons d'un certain point et en prenant soin de ne pas bouger. La vérité de l'image qu'il nous propose n'est donc pas absolue. Elle est conforme à ce que l'on voit dans certaines circonstances, elle ne correspond que partiellement à ce que l'on sait à ce que l'on sent. Ce visage par exemple que je regarde de face, il se peut que j'en connaisse aussi le profil. Mais comme je ne remarque pas ce dernier à l'endroit où je me trouve, il ne figurera pas dans mon image si je la veux naturaliste. Le peintre, en revanche, qui ne se laissera pas limiter par ce qu'il aperçoit à un moment donné (Braque ou Picasso, par exemple), pourra me présenter les deux aspects du visage en même temps. Et il m'en révélera ainsi la réalité de façon plus complète que ne le fait celui qui adopte la manière dite naturaliste. (MULLER, $1963: 19-20)^{2}$.

\footnotetext{
2"No entanto, se o naturalismo não é o estado normal da arte, não é pelo menos o seu estado ideal? Não é o único meio de dar uma imagem verdadeira da realidade? É somente o meio de representar as coisas tais quais elas aparecem aos nossos olhos quando nós as consideramos de um certo ponto e tomando cuidado de não nos movermos. A verdade da imagem que ele nos propõe não é, portanto, absoluta. Ela se dá conforme ao que se vê em certas circunstâncias, ela corresponde só e parcialmente ao que se sabe, ao que
} 
O abandono da perspectiva, a experimentação sistemática e insistente à procura de soluções técnicas, a fim de criar um novo espaço plástico, são as características essenciais atribuídas à pintura cubista.

A técnica de representação de objetos por meio de diversos ângulos de visão já é verificada no famoso quadro do pintor espanhol, Les Demoiselles d'Avignon de 1907, que marca definitivamente o fim da fase rosa e o início do cubismo pictural. A mulher contemplada, neste quadro, no primeiro plano à direita, é representada de acordo com duas visões opostas que se conjugam na tela, ou seja, vemos ao mesmo tempo o corpo da figura de costas e seu rosto de frente. As duas mulheres representadas no meio da compjosição têm seus rostos ora focalizados de perfil ora de frente. O novo modo de representação do espaço, presente nas produções artísticas de Picasso de 1907 até 1917, despertará a atenção de vários amantes da pintura e de escritores já reconhecidos como Apollinaire. Este será defensor apaixonado da escola cubista e pronunciará que Picasso e Braque conseguem transportar para a tela não só as três dimensões do espaço, mas também a polêmica quarta dimensão tão especulada pelas ciências físicas.

No início da década de vinte, o estudo, por parte de críticos literários e de arte, da técnica por intermédio da qual um objeto é representado segundo vários ângulos de visão, possibilitou o primeiro cotejo entre a estética proustiana e a estética cubista. Em 1923, um ano após a morte de Marcel Proust, Fernand Gregh em L'bommage escreveu que o olhar do escritor da monumental obra

\footnotetext{
se sente. Este rosto, por exemplo, que eu olho de frente, é possivel que eu conheça também o seu perfil. Mas como eu não reparo este último no lugar em que me encontro, ele não figura na minha imagem se eu a quero naturalista. $O$ pintor, em contrapartida, que não se deixará limitar pelo que ele percebe em um determinado momento (Braque ou Picasso, por exemplo), poderá me apresentar os dois aspectos do rosto ao mesmo tempo. E ele me revelará assim a realidade de um modo mais completo do que aquele que adota a maneira dita naturalista." [Tradução da autora]
} 
Em Busca do Tempo Perdido era como o das moscas, ou seja: "un

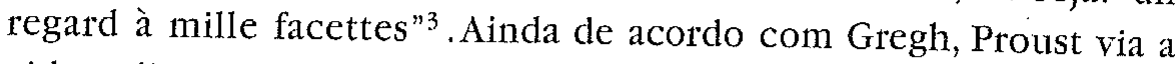
vida poligonalmente:"il voyait les vingt côtés d'une question, et en ajoutait un vingt-et-unième qui était un prodige d'invention et d'ingéniosité." (Apud FRAISSE, $1988: 65)^{4}$. O comentário do crítico francês facultou a Luc Fraisse, autor do livro Le Processus de la Création chez Marcel Proust, comparar esse olhar admiravelmente poligonal do escritor francês ao olhar do pintor cubista, cuja grande virtude era representar um motivo a partir de vários ângulos de visão na extensão da tela.

Entretanto, a analogia estabelecida por Fraisse não se apoiou em nenhum texto, em particular, da obra de Marcel Proust. Pretendo, neste ensaio, citar quatro passagens do volume $O$ Caminbo de Guermantes em que verifico o olhar múltiplo proustiano do qual falam Gregh e Fraisse e ao qual este último comparou o modo de olhar dos pintores cubistas.

O primeiro trecho difere fundamentalmente dos outros, embora já apresente a maneira diversificada como o escritor francês narrava um fato, descrevia uma face, um objeto ou, simplesmente, uma situação. Ele se diferencia ao reverberar mais um projeto filosófico do autor de Em Busca do Tempo Perdido do que um projeto estético norteado pelas novas tendências da arte moderna. No en-tanto, aposto na pertinência do conteúdo da passagem, posto que revela o olhar múltiplo do escritor que verificarei, mais tarde, representado tanto por meio do conteúdo quanto por meio da forma textual:

Je comprenais que ce qui m'avait paru ne pas valoir vingt francs quand cela m'avait été offert pour vingt francs dans la maison de passe où c'était seulement pour moi une femme désireuse de

\footnotetext{
3 "um olhar com mil facetas" [T.A.].

" "Ele via os vinte lados de uma questão e ajuntava-lhe um vigésimo primeiro que era um prodígio de invenção e de engenhosidade" [T.A.].
} 
gagner vingt francs, peut valoir plus qu'un million, que toutes les situations enviées, plus même que les tendresses de famille, si on a commencé par imaginer en elle un être mystérieux, curieux à connaître, difficile à saisir, à garder Sans doute c'était le même mince et étroit visage que nous voyions Robert et moi. Mais nous étions arrivés à lui par deux routes opposées qui ne communiqueraient jamais, et nous n'en verrions jamais la même face. Ce visage, avec ses regards, ses sourires, les mouvements de sa bouche, moi je l'avais connu du debors comme étant celui d'une femme quelconque qui pour vingt francs ferait tout ce que je voudrais. Aussi les regards, les sourires, les mouvements de bouche mavaient paru seulement significatifs d'actes généraux, sans rien d'individuel, et sous eux je n'aurais pas eu la curiosité de chercher une personne. Mais ce qui m'avait en quelque sorte été offert au départ, ce visage consentant, ç'avait été pour Robert un point d'arrivée vers lequel il s'était dirigé à travers combien d'espoirs, de doutes, de soupçons, de rêves! (PROUST, 1954)

Nesta passagem, o narrador-personagem Marcel apresenta uma mulher, Rachel, através de duas opiniões distintas, a sua e a de seu amigo Robert de Saint-Loup. Nota-se uma diferença fundamental entre este tipo de descrição e a representação imagética dos pintores cubistas. No texto de Marcel Proust, a figura de uma só mulher é construída por meio de duas visões diferentes, formuladas por duas pessoas situadas em pontos distintos em relação ao objeto. Enquanto na composição pictural cubista, o mesmo motivo é representado conforme vários ângulos de visão, porém a partir do olhar de um só indivíduo, o pintor.

Em contrapartida, o trecho está imbuído de uma proposta que perpassa toda a obra proustiana, baseada na convicção da existência

\footnotetext{
5 "Compreendia que o que me parecera não valer vinte francos quando me fora oferecido por vinte francos numa casa de tolerância, ou quando era apenas para mim uma mulher desejosa de ganhar vinte francos, pode valer mais que um milhão, que a família, que todas as posições invejadas, se se começou por imaginar nela um ser desconhecido, curioso de conhecer, difícil de apanhar, de conservar. Era sem dúvida o mesmo rosto fino e miúdo que víamos Robert e eu. Mas tínhamos chegado a ele por dois caminhos opostos que jamais se comunicarão e nunca the veríamos a mesma face. Aquele rosto, com os seus
} 
de uma realidade construída a cada instante, efetivamente móvel e subjetiva, na medida em que se produz diferentemente em cada indivíduo. Conforme as palavras do narrador, a face de Rachel nunca seria vista da mesma forma por ele e por Saint-Loup, já que os dois edificaram imagens diversas da mesma pessoa, calcadas respectivamente na indiferença do narrador que a conhecia como uma cortesã e no fascínio de Saint-Loup que via, em Rachel, uma atriz formidável.

Estabelecendo uma comparação com a pintura cubista, é justo afirmar que esta adota uma proposta análoga, primeiramente, por representar todos os lados de um objeto em seus quadros de modo a oferecer uma apreensão total do motivo e, posteriormente, por transmitir a visão singular do pintor ao reproduzir não somente as características visuais de uma face, mas também seus traços psicológicos mais expressivos, capturados pelo olhar investigador do artista. Assim, verifica-se, nos primeiros anos do cubismo, uma tentativa de abranger concretamente toda a realidade por meio da transposição para a tela da representação completa de um objeto, mesmo quando, logicamente, ele nunca caberia inteiro no campo de visão do pintor e, posteriormente, verifica-se a multiplicação da mesma realidade, tão cara a Marcel Proust, por intermédio da representação fiel dos traços psicológicos que um rosto pode comportar,mas que somente o olhar peculiar do artista rastreia e suas mãos, que manipulam ágil e corretamente o pincel, transferem para a tela. Segundo Ernest Curtius, crítico literário que também estudou as possíveis relações entre a estética proustiana e a estética cubista, a realidade tanto em uma quanto em outra figura-se fragmentada e multiplicada.

olhares, os seus sorrisos, os movimentos de sua boca, eu o conhecera de fora, como o de uma mulher qualquer que faria por vinte francos tudo quanto eu quisesse. Assim os olhares, os sorrisos, os movimentos de boca me haviam parecido apenas significativos de atos gerais, sem nada de individual, e sob eles eu não teria a curiosidade de procurar uma pessoa. Mas o que me fora de algum modo oferecido na partida, esse rosto condescendente, fora para Robert um ponto de chegada, para o qual se havia dirigido através de quantas esperanças, dúvidas, suspeitas, sonhos!" (PROUST, 1994:142-143). 
"Que chaque sujet possède son point de vue propre ne signifiera plus une dissolution de l'objectif mais une multiplication du réel. Chaque point de vue subjectif crée un nouvel objet, (...) multiplie les dimensions de l'être et de la connaissance, et étend le domaine de la vérité" et il complète: "le relativisme proustien marque, selon nous, un tournant de la pensée bumaine dont on n'a pas encore mesuré l'importance, comme de la nouvelle figuration de l'espace où s'est engagée la peinture moderne".(Apud FRAISSE, $1988: 195)^{6}$

A segunda passagem, com a qual irei trabalhar, dá ainda mais expressão à analogia entre as duas estéticas, uma vez que nela figuram somente o "narrador-personagem" eAlbertine de forma que se tem, respectivamente, um único observador que descreverá o objeto. Marcel perceberá o rosto da jovem por meio de mudanças de perspectiva, entrevendo mil formas diferentes desencadeadas por um mesmo rosto ao longo do tempo. Chamo atenção para o aspecto formal do texto que revela, aqui, um projeto estético de Marcel Proust influenciado ${ }^{7}$ pelas novas tendências da Arte Moderna, sobretudo, pela pintura cubista.

Bref, de même qu'à Balbec, Albertine m'avait souvent paru différente, maintenant - comme si, en accélérant prodigieusement la rapidité des changements de perspective et des changements de coloration que nous offre une personne dans nos diverses rencontres avec

\footnotetext{
${ }^{6}$ 'Que cada pessoa possua seu ponto de vista próprio não significará mais uma dissolução do objetivo mas uma multiplicação do real. Cada ponto de vista cria um novo objeto, (...) multiplica as dimensões do ser e do conhecimento, e estende o domínio da verdade" e ele completa: "O relativismo proustiano marca, na nossa opinião, uma grande mudança do pensamento humano cuja importância ainda não se avaliou, como da nova figuração do espaço em que se engajou a pintura moderna". [T.A.]

${ }^{7}$ Os estudos referentes à comparação entre a pintura moderna e a obra proustiana, remontam ao início da década de 20.(cf. UENISHI, 1988). A denominação de obra impressionista, dada ao romance, Em Busca do Tempo Perdido, é resultado de uma analogia patente que aproxima a obra de Marcel Proust da pintura impressionista. Ademais, o próprio autor, a longo de seu livro, compara sua obra, por diversas vezes, a um quadro, além de afirmar que a função do escritor se assemelha à função desempenhada pelo pintor. (cf. PICHON, 1990). A partir da leitura da biografia de Marcel Proust, escrita por Jean-Yves
} 
elle, j'avais voulu les faire tenir toutes en quelques secondes pour recréer expérimentalement le phénomène qui diversifie l'individualité d'un être et tirer les unes des autres, comme d'un étui, toutes les possibilités qu'il enferme - dans ce court trajet de mes lèvres vers sa joue, c'est dix Albertine que je vis; cette seule jeune fille étant comme une déesse à plusieurs têtes, celle que j'avais vue en dernier, si je tentais de m'approcher d'elle, faisait place à une autre. (PROUST, 1954) ${ }^{8}$

É interessante observar a maneira como o narrador descreve a face da jovem de Balbec. De início, declara que, num vislumbre, contempla os diversos rostos que ela o apresentou no curso de inúmeros encontros, depois, afirma querer reunir as faces a fim de apreender o que as diferencia por intermédio de uma experimentação indubitavelmente plástica, uma vez que o narrador trabalha somente com imagens de Albertine. Este desejo se assemelha particularmente ao do pintor cubista que procura reproduzir na tela todas as possibili-dades de um objeto.

Visando tornar o cotejo ainda mais nítido, destaco as palavras próprias do universo plástico escolhidas cuidadosamente pelo autor, tais como: perspectiva e coloração ou, a expressão facilmente

Tadié, é possível confirmar a paixão que Proust nutria pelas artes plásticas, sobretudo, pela obra de Monet que, segundo numerosos críticos, serviu de modelo para a criação do personagem Elstir, eminente pintor de Em Busca do Tempo Perdiclo. Ainda, conforme as informações oferecidas porTadié, Proust, não somente admirava a obra de vários pintores modernos, mas também os conhecia pessoalmente. A titulo de exemplo, pode-se citar Picasso e de Braque, ambos, grandes expoentes da estética cubista. (cf.TADIÉ, 1996)

8 "Em suma, da mesma forma que em Balbec, Albertine muitas vezes me parecera diferente, agora, como se ao acelerar prodigiosamente a rapidez das mudanças de perspectiva e das mudanças de coloração que nos oferece uma pessoa em nossos diversos encontros com ela, eu quisesse fazê-los caber todas em alguns segundos para recriar experimentalmente o fenômeno que diversifica a individualidade de um ser e tirar uma das outras como de um estojo, todas as possibilidades que ele encerra, naquele curto trajeto de meus lábios para a sua face foram dez Albertine que eu vi; como aquela única moça era uma deusa de várias cabeças, a que eu tinha visto por último, quando tentava aproximarme dela, cedia Iugar a outra mais." (PROUST, 1994: 329-330). 
adaptada às figuras recriadas pela escola cubista, como: deusa de várias cabeças. Não posso deixar de assinalar a presença de uma realidade múltipla que oscila segundo diversas variáveis, seja por meio da opinião de pessoas diferentes, como verificou-se no primeiro exemplo, seja por meio da passagem do tempo, como neste último.

Luc Fraisse, em seu livro Le Processus de la Création chez Marcel Proust, procura fundamentar sua teoria sobre as relações de Proust com o Cubismo por intermédio de críticas literárias realizadas no passado, mormente aquelas enunciadas na década de 20 . Já citei a opinião de Fernand Gregh sobre o olhar perscrutador do escritor francês, bem como a de Ernest Curius referente ao relativismo do ponto de vista tanto na literatura proustiana quanto na própria Arte Moderna. Neste momento, pretendo mencionar a crítica efetuada por Jacques Rivière que aborda mais a forma, propriamente dita, do que o efeito produzido pelas técnicas da pintura cubista na obra proustiana. Jacques Rivière assinala, particularmente, os traços psicológicos observados pelos pintores no motivo que transparecem no quadro cubista por meio de imagens e que, segundo o autor, também figuram na obra proustiana por meio da descrição de personagens.

Dans le cubisme, mélange d'éléments idéaux ou psychologiques de l'objet avec des éléments au maximum concrets (...): chez Proust, constant mélange, dans la description, d'un élément intérieur; émotif, d'ailleurs construit comme s'il faisait partie des choses (...). (Apud FRAISSE, $1988: 195)^{9}$

A este comentário, muito perspicaz de Jacques Rivière, eu acrescento que, tal como a pintura cubista, o objeto representado, na obra proustiana, ganha a forma de um elemento espacial ou psico-

\footnotetext{
"No cubismo, mescla de elementos ideais ou psicológicos do objeto com elementos extremamente concretos (...): em Proust, constante mescla, na descrição, de um elemento interior, emotivo, aliás construído como se ele fizesse parte das coisas (...)".[T.A.]
} 
lógico ao qual ele está associado.Assim, em O Caminbo de Guermantes, a senhora de Guermantes é descrita com todos os elementos que constituem o Faubourg Saint-Germain. O narrador via na personagem todo o ambiente que ela freqüentava, não só de uma maneira psicológica, mas também visivelmente plástica.

Comme nous localisons dans le corps d'une personne toutes les possibilités de sa vie, le souvenir des êtres qu'elle connaît et qu'elle vient de quitter, ou s'en va rejoindre, si, ayant appris par Françoise que Mme de Guermantes irait à pied déjeuner chez la princesse de Parme, je la voyais vers midi descendre de chez elle en sa robe de satin chair, au-dessus de laquelle son visage était de la même nuance, comme un nuage au soleil coucbé, c'était les plaisirs du faubourg Saint-Germain que je voyais tenir devant moi, sous ce petit volume, comme dans une coquille, entre ces valves glacées de nacre rose. (PROUST, 1954) $)^{10}$

No início desta terceira passagem, o narrador faz uma pequena introdução, que prepara o leitor para a imagem que ele lhe oferecerá, explicando que uma pessoa conserva em seu corpo as lembranças dos indivíduos que conhece, dos lugares que freqüenta. Assim, Marcel edifica sua própria teoria estética de forma a aplicá-la, em seguida, a Oriane de Guermantes amalgamando-a livremente à ambientação que envolvia o Faubourg Saint Germain. Este trecho comprova efetivamente as palavras de Rivière, segundo as quais tanto em Proust quanto na estética cubista, há elementos psicológicos do objeto que se misturam com seu aspecto visual, constituindo uma só imagem.

\footnotetext{
${ }^{10 "}$ Como localizamos no corpo de uma pessoa todas as possibilidades da sua vida, a lembrança das criaturas que conhece e que acaba de deixar ou com quem vai encontrase, quando eu sabia por Françoise que a Sra. de Guermantes ia sair para almoçar em casa da princesa de Parma, quando a via descer pelo meio-dia, com o seu vestido de cetim claro, acima do qual o seu rosto era da mesma nuança, como uma nuvem ao sol poente, eram todos os prazeres do Faubourg Saint Germain que eu via ali diante de mim, naquele primeiro volume, como uma concha, entre aquelas brunidas valvas de rosado nácar." (PROUST, 1994:33).
} 
Em Homme à la Clarinette (1911) de Picasso, encontra-se a mesma estrutura. O músico que figura no centro da composição toma emprestada a forma plástica de seu instrumento, o clarinete. Há uma fusão visual de quem toca e do que é tocado no quadro do pintor espanhol.

No terceiro trecho que destaquei de $O$ Caminho de Guermantes, Oriane se funde ao Faubourg Saint-Germain, ou melhor, aos prazeres do local. Na quarta e última passagem que analisarei, Albertine, personagem que igualmente transita nas páginas de Em Busca do Tempo Perdido, é descrita como se contivesse em sua face todas as praias de Balbec. Deste modo, há uma mescla entre os elementos espaciais situados no local, onde o personagem-narrador conhece a jovem, e a própria imagem de seu rosto, em mais uma descrição cubista reali-zada por Marcel Proust.

D'autre part Albertine tenait, liées autour d'elle, toutes les impressions d'une série maritime qui m'était particulièrement cbère. Il me semblait que j'aurais, sur les deux joues de la jeune fille, embrassé toute la plage de Balbec.(PROUST, 1954) ${ }^{11}$

Ao longo do ensaio, foi meu intuito estabelecer uma comparação entre a estética proustiana e a estética cubista me embasando em críticas literárias que já, de alguma forma, propuseram esta analogia e, sobretudo, na semelhança entre o método de descrição de personagens na obra de Marcel Proust e as técnicas picturais empregadas em grande parte nos quadros do pintor espanhol Pablo Picasso. A estratégia de descrever um objeto segundo vários ângulos de visão, tão presente nos quadros cubistas, foi identificada tanto na passagem em que o narrador descrevia Rachel segundo seu ponto de vista e de seu amigo Saint Loup, quanto no segundo trecho analisado em

\footnotetext{
11 "Por outro Iado, tinha Albertine, reunidas em redor de si, todas as impressões de uma série marítima que me era particularmente cara. Parecia-me que poderia, em duas faces, beijar toda a praia de Balbec". (Proust, 1994:327).
} 
que Marcel se maravilha perante as diversas faces resgatadas por sua memória, que apareciam e desapareciam enquanto contemplava Albertine. Outra característica que uniu estas duas estéticas foi a colisão entre elementos psicológicos ou espaciais, associados ao objeto representado, e o aspecto visual deste que surge tanto na descrição da Senhora de Guermantes, que é vista juntamente com os prazeres do Faubourg Saint Germain, ou no trecho em que Albertine é descrita como se sua face abarcasse as praias de Balbec, ou ainda no quadro Homme à la Clarinette, de Picasso.

O que me parece claro, depois de toda a pesquisa realizada, é que o escritor francês Marcel Proust efetivamente transportava para sua obra elementos com os quais trabalhavam as artes plásticas, com o intuito de, não somente criar uma estética literária moderna e original, mas também e, especialmente, mostrar que a realidade é construída diferentemente por cada pessoa ou, ademais se transforma continuamente segundo uma mesma pessoa com a passagem do tempo, tornando-se um espaço extremamente móvel, subjetivo e multiplicado.

Résumé : Marcel Proust était un grand connaisseur et amateur des arts plastiques. Je présente ici une étude sur la construction des personnages proustiens dans Le Côté de Guermantes au moyen des tecbniques picturales des peintres cubistes. Je souligne la méthode de reproduction d'un objet à partir de plusieurs angles de vision, transportée par Proust dans la description du visage d'un personnage, constitué par l'ensemble de quelques images de cette face textuelle. 


\section{Referências bibliográficas}

FRAISSE, Luc. Le Processus de la Création cbez Marcel Proust. Paris: José Corti, 1988.

MULLER, Joseph-Emile. L'Art Moderne. Paris: Librairie Générale Française, 1963.

PICHON,Yann le. Le Musée Retrouvé de Marcel Proust. Paris: Stock,1990. PROUST, Marcel. Le Côté de Guermantes. Paris: Gallimard, 1954.

PROUST, Marcel. O Caminbo de Guermantes.Tradução de Mário Quintana. São Paulo: Globo, 1994.

TADIÉ, Jean-Yves. Marcel Proust. Paris: Gallimard, 1996.

UENISHI, Taeko. Le style de Proust et la peinture. Paris: SEDES, 1988.

WALTHER, Ingo F Pablo Picasso: O Gênio do Século. Köln:Benedikt Taschen, 1994. 